\title{
Alveolar soft-part sarcoma presenting with eosinophilia and shunt
}

\author{
M Almansori MBBS ${ }^{1}$, AR Turner MDCM FRCPC ${ }^{1}, S_{\text {Girgis MD FRCPC }}^{2}$, D Vethanayagam MD FRCPC ${ }^{1}$
}

\author{
M Almansori, AR Turner, S Girgis, D Vethanayagam. Alveolar \\ soft-part sarcoma presenting with eosinophilia and shunt. \\ Can Respir J 2005;12(7):389-391.
}

\begin{abstract}
Alveolar soft-part sarcoma (ASPS) is a rare soft tissue tumour found in young adults that usually arises in skeletal muscle and occurs most frequently in the lower limbs. Radiological and pathological findings of ASPS in a 34-year-old man who presented with increasing shortness of breath over a period of four to six weeks with peripheral blood eosinophilia, hypoxemia and a significant arteriovenous shunt are reported. The present article is the fourth report of eosinophilia in association with sarcoma, and the first involving ASPS.
\end{abstract}

Key Words: Eosinophils; Sarcoma; Shunt

\section{Un sarcome alvéolaire des tissus mous accompagné d'une éosinophilie et d'une anastomose}

\begin{abstract}
Chez les jeunes adultes, le sarcome alvéolaire des tissus mous (SATM) est une rare tumeur des tissus mous qui se forme généralement dans le muscle squelettique des membres inférieurs. Les observations radiologiques et pathologiques du SATM chez un homme de 34 ans venu consulter pour un essoufflement croissant en l'espace de quatre à six semaines, accompagné d'une éosinophilie périphérique, d'une hypoxémie et d'une importante anastomose artérioveineuse, sont présentées. Le présent article constitue le quatrième compte rendu d'éosinophilie en association avec un sarcome, mais c'est le premier à mettre en cause le SATM.
\end{abstract}

\section{CASE PRESENTATION}

A 34-year-old, previously healthy man presented with a sixweek history of dyspnea and a mass on the left leg that had been present for six months. Clinical features included a cough, hemoptysis and a $18.1 \mathrm{~kg}$ weight loss. His oxygen saturation was $86 \%$ with room air and $93 \%$ with supplemental oxygen $(5 \mathrm{~L} / \mathrm{min}$ by nasal cannula). He had a $5 \mathrm{~cm} \times 8 \mathrm{~cm}$ fluctuant mass on the lateral aspect of his left leg, just below the knee.

The patient's blood count showed eosinophilia $\left(1.3 \times 10^{9} / \mathrm{L}\right.$ [normal $0.0 / \mathrm{L}$ to $0.7 \times 10^{9} / \mathrm{L}$ ]), with a normal total white blood cell count of $8.3 \times 10^{9} / \mathrm{L}$. Electrolytes, renal function and liver enzymes were normal. Plain films (Figure 1A) and computed tomography (CT) of the thorax (Figure 1B) showed numerous (more than 100) well-circumscribed nodules in the lower and mid-lung zones ranging from $2 \mathrm{~mm}$ to $16 \mathrm{~mm}$ in diameter.

Pulmonary function tests showed mild obstruction, with a forced expiratory volume in $1 \mathrm{~s}$ of $3.13 \mathrm{~L}$ (71\% predicted), a forced vital capacity of $4.86 \mathrm{~L}$ (91\% predicted) and no change postbronchodilator. Total lung capacity was normal $(8.18 \mathrm{~L}$ or $116 \%$ predicted) and mild gas trapping was noted. Diffusion was normal. A shunt analysis showed a $20 \%$ shunt. CT of the chest did not show feeding vessels to any of the nodules. An echocardiogram was not performed.

The patient's leg mass was confirmed on plain film to be of soft tissue origin. Ultrasound confirmed this to be a vascular mass. Magnetic resonance imaging (MRI) showed this lesion to be located within the deep musculature of the lateral compartment of the lower left leg, just below the knee (Figure 2), with heterogeneous signalling (intermediate-decreased T1 with increased T2 signal intensity). It was a highly vascular lesion.

A needle core biopsy of the left lower leg lesion (Figure 3A) showed malignant cells arranged in an alveolar/organoid pattern. Tumour aggregates were separated by thin-walled endothelial-lined vascular channels, and exhibited small-tointermediate, rounded-to-polygonal nuclei. The cytoplasm was abundant and exhibited an acidophilic, granular appearance. Strong cytoplasmic staining resistant to diastase was noted with periodic acid-Schiff staining (Figure 3B). Immunophenotyping studies were negative for low-molecular-weight cytokeratin, myogenin, desmin, actin and s-100 protein. CD34 staining highlighted the vascular channels within the tumour lobules, but the tumour cells were negative; staining with vimentin was weakly positive. This pattern of staining was consistent with alveolar soft-part sarcoma (ASPS) (see Discussion). High-power examination (100× under oil) revealed numerous granules and crystals that were further identified by electron microscopy.

The patient complained of severe headaches, for which he was evaluated using CT and MRI of the brain, but no abnormalities could be identified and a lumbar puncture was negative for malignant cells.

The patient received one cycle of chemotherapy (MAID-G protocol [mesna, ifosfamide, doxorubicin dacarbazine and granulocyte colony-stimulating factor]) $(1,2)$, which was discontinued due to lack of response. He died of respiratory failure four months following the initial diagnosis. The eosinophilia persisted throughout.

\section{DISCUSSION}

Soft tissue sarcomas are cancers of connective tissue including muscle, tendon, fat, fibrous tissue, synovial tissue, vessels and nerves. Sixty per cent of soft tissue sarcomas arise in the extremities, with the lower extremities being three times more likely to be involved than the upper extremities. Thirty per cent of soft tissue sarcomas arise in the trunk, with a large proportion of these arising in the retroperitoneum. Fewer are seen in the head and neck region.

Departments of ${ }^{1}$ Medicine and ${ }^{2}$ Laboratory Medicine and Pathology, University of Alberta, Edmonton, Alberta

Correspondence and reprints: Dr Dilini Vethanayagam, 2E4.29 Walter C Mackenzie Centre, 8440 - 112 Street Northwest, Edmonton,

Alberta T6G 2B7. Telephone 780-407-1479, fax 780-407-6384, e-mail dilini.vethanayagam@ualberta.ca 

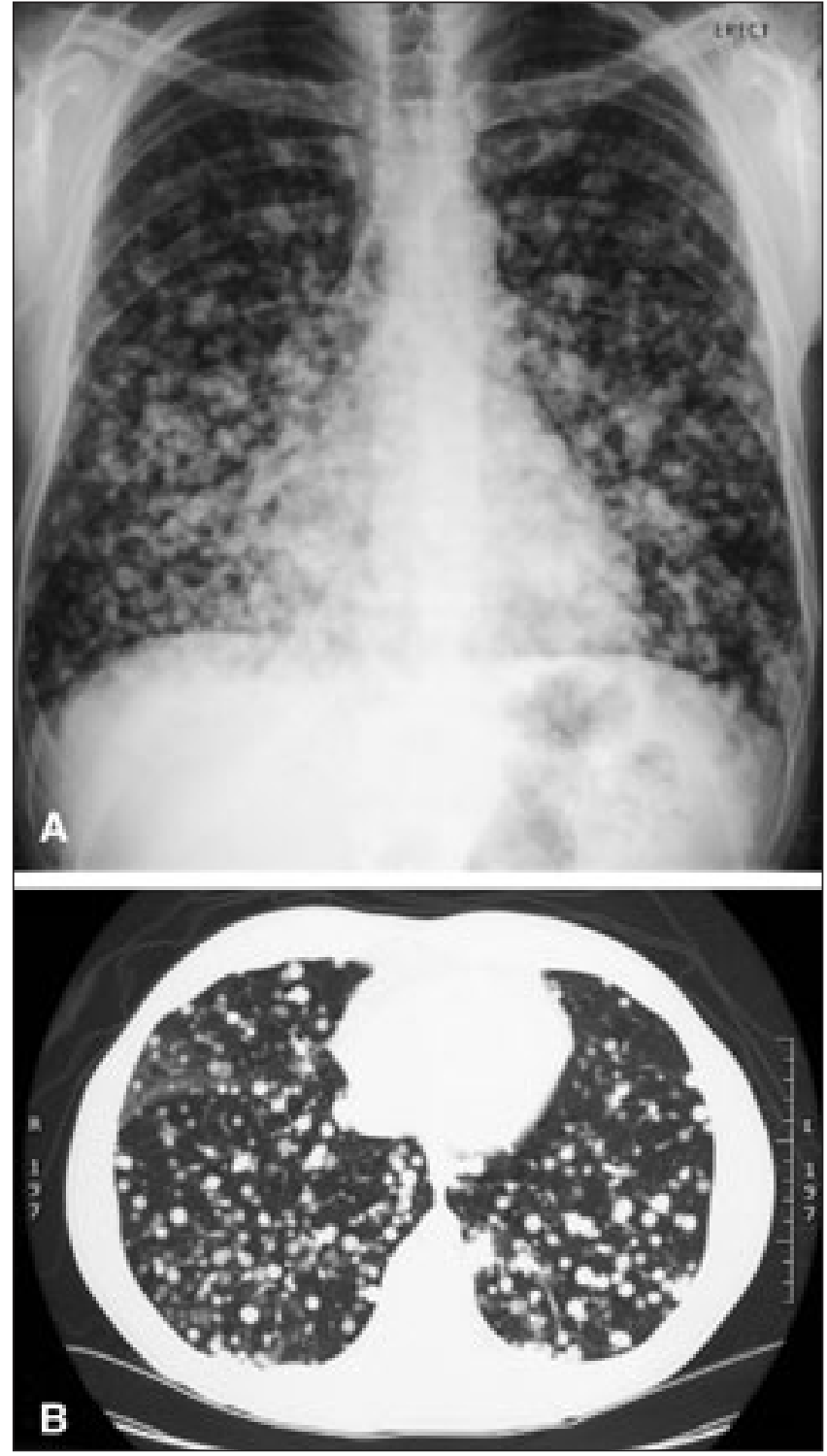

Figure 1) A Plain chest radiograph. B Computed tomography of the chest showing numerous well-circumscribed nodules scattered throughout the lungs. Of note, the computed tomography was not high resolution and, therefore, intratumoural vascular dilation was not seen

The most common presentation of soft tissue sarcomas is an asymptomatic mass. Mechanical symptoms referable to pressure, traction or entrapment of nerves or muscles may be present (3).

In 1952, Christopherson et al (4) described a unique soft tissue tumour composed of cells with granular cytoplasm arranged along delicate fibrous septa, giving rise to an alveolar or organoid pattern. For this reason, they named the lesion 'alveolar soft-part sarcoma.' The tumour contained numerous vascular channels around the clusters of tumour cells, reminiscent of a paraganglioma or an endocrine neoplasm.

ASPS is usually a disease of young adults (mean age 25 years) (5). One report (6) demonstrated a chromosomal translocation in association with this tumour $(\mathrm{t}[\mathrm{X} ; 17][\mathrm{p} 11 ; \mathrm{q} 25])$. The disease has an indolent clinical course with relatively low rates of local and distant recurrence. The lung and brain are common sites of metastases. Brain metastases were only observed as part of a more disseminated disease (7).

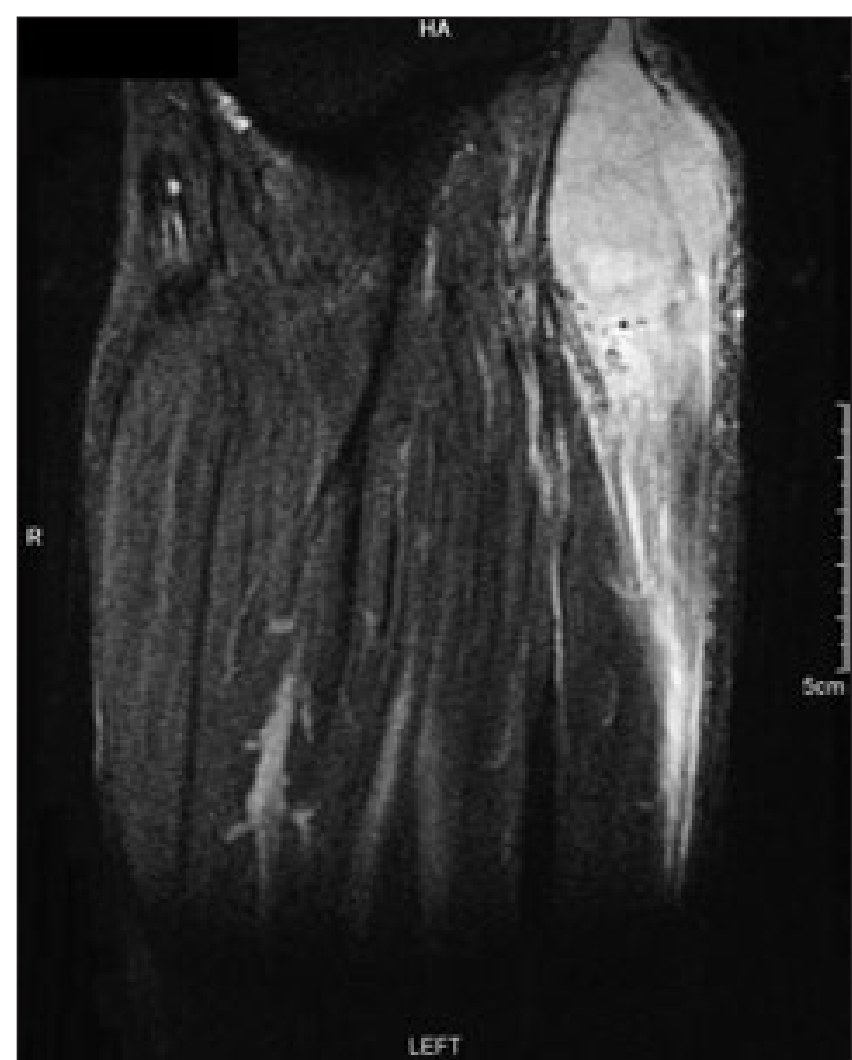

Figure 2) Magnetic resonance image of soft tissue abutting the lateral aspect of the left tibia and showing increased T2 signal intensity

High signalling on T1-weighted MRI images of our patient's leg and numerous signal voids were highly suggestive of ASPS (8). ASPS is a highly vascular tumour and, on enhanced CT of the chest, some of the masses contain dilated and tortuous intratumoural vessels (9). These vessels likely account for the $20 \%$ shunt noted in the pulmonary function tests.

Most sarcomas metastasizing to the lung produce large nodules ('cannon balls'). The chest radiograph of our patient was unusual, showing much smaller lesions.

Cytological detection of characteristic crystalloids using a Papanicolaou smear from a needle core biopsy is characteristic of ASPS $(10,11)$, and facilitated the final pathological diagnosis of our patient.

Eosinophilia has been found in patients with lymphomas and a variety of other solid tumours. Along with its substantial role in immunomodulation, we are beginning to recognize the importance of eosinophils in neoplastic disorders (12). Eosinophilia may be associated with a positive prognostic significance in some tumours $(13,14)$ and a negative influence in others $(15,16)$. In addition, eosinophilia has been associated with a good response to treatment in some malignancies (17). Removal of the primary neoplasm sometimes corrects the eosinophilia, and tumours have been found that produce eosinopoietic cytokines such as interleukin-5 and granulocyte/ macrophage colony-stimulating factors. Eosinophilia could be a marker of a patient's immune system activation (18).

Three other cases of sarcoma causing eosinophilia have been recently reported (19-21). One case reported an undifferentiated embryonal sarcoma arising in a pediatric patient with mesenchymal hamartoma of the liver (19). Another case 


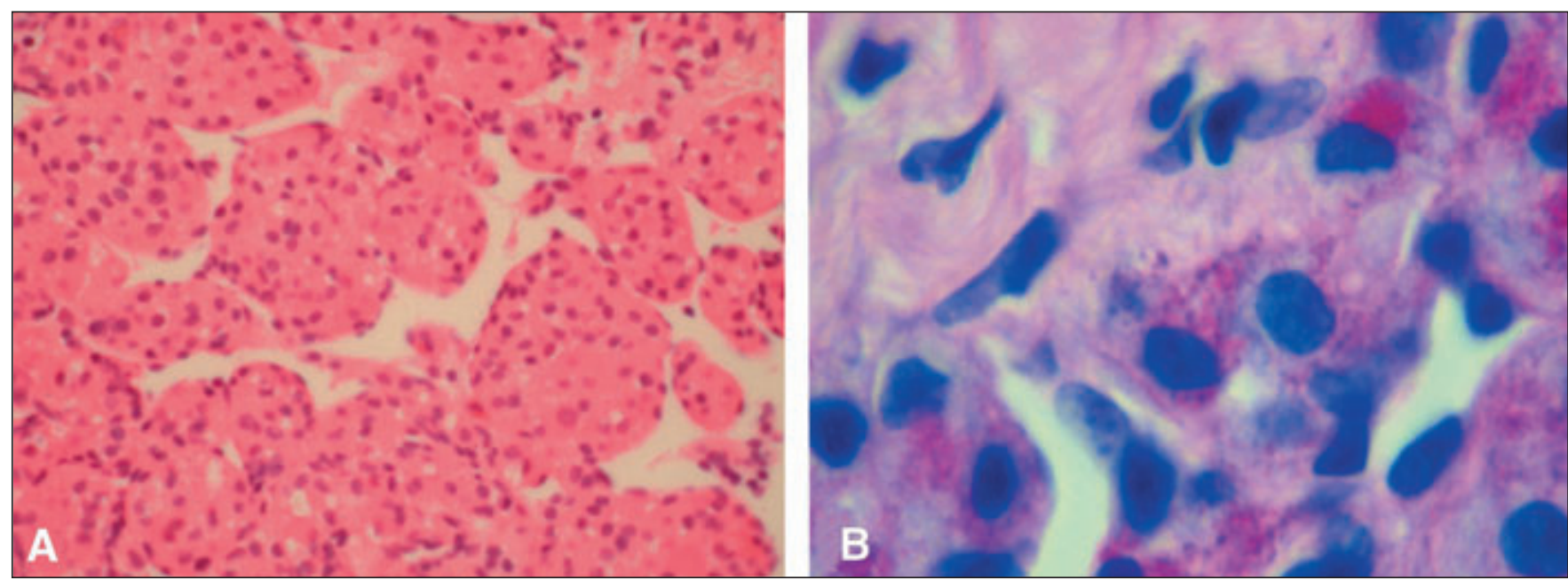

Figure 3) A Hematoxylin and eosin stain (original magnification $\times 400$ ) showing malignant cells arranged in an alveolar pattern. B Periodic acidSchiff stain (original magnification $\times 1000$ ) showing dark pink, periodic acid-Schiff stain-positive, intracytoplasmic granules

reported eosinophilia associated with a cardiac rhabdomyosarcoma (20). A third case involved a 67-year-old woman with a uterine leiomyosarcoma in which the tumour was heavily infiltrated with eosinophils, suggesting the patient's immune system was trying to control the tumour growth (21). Our case represents the first report of eosinophilia associated with ASPS.

\section{CONCLUSIONS}

The present report highlights the association of eosinophilia with sarcoma. ASPSs have a poor outcome. In one series,

\section{REFERENCES}

1. DeLaney TF, Spiro IJ, Suit HD, et al. Neoadjuvant chemotherapy and radiotherapy for large extremity soft-tissue sarcomas. Int J Radiat Oncol Biol Phys 2003;56:1117-27.

2. Patel SR, Benjamin RS. The role of chemotherapy in soft tissue sarcomas. Cancer Control 1994;1:599-605.

3. Patel SR, Benjamin RS. Soft tissue and bone sarcomas and bone metastases. In: Fauci AS, ed. Harrison's Principles of Internal Medicine, 15th edn. New York: McGraw-Hill, 2001:625-6.

4. Christopherson WM, Foote FW Jr, Stewart FW. Alveolar soft-part sarcomas; structurally characteristic tumors of uncertain histogenesis. Cancer 1952;5:100-11.

5. Park YK, Unni KK, Kim YW, et al. Primary alveolar soft part sarcoma of bone. Histopathology 1999;35:411-7.

6. Heimann P, Devalck C, Debusscher C, Sariban E, Vamos E. Alveolar soft-part sarcoma: Further evidence by FISH for the involvement of chromosome band 17q25. Genes Chromosomes Cancer 1998;23:194-7.

7. Portera CA Jr, Ho V, Patel SR, et al. Alveolar soft part sarcoma: Clinical course and patterns of metastasis in 70 patients treated at a single institution. Cancer 2001;91:585-91.

8. Suh JS, Cho J, Lee SH, et al. Alveolar soft part sarcoma: MR and angiographic findings. Skeletal Radiol 2000;29:680-9.

9. Choi JI, Goo JM, Seo JB, Kim HY, Park CK, Im JG. Pulmonary metastases of alveolar soft-part sarcoma: CT findings in three patients. Korean J Radiol 2000;1:56-9.

10. Machhi J, Kouzova M, Komorowski DJ, et al. Crystals of alveolar soft part sarcoma in a fine needle aspiration biopsy cytology smear. A case report. Acta Cytol 2002;46:904-8.

11. Logrono R, Wojtowycz MM, Wunderlich DW, Warner TF, Kurtycz DF. Fine needle aspiration cytology and core biopsy in the diagnosis of alveolar soft part sarcoma presenting with lung metastases. A case report. Acta Cytol 1999;43:464-70. the median survival was 48 months (22). ASPS has a $38 \%$ overall five-year survival, and $48 \%$ if the disease is localized. A significant reduction in survival is seen in the presence of hematogenous metastases, with a median survival of eight months (range zero to 45 months) (22). With a potential immunomodulatory role in sarcomas, eosinophils are now recognized to have more than a simple presence in tumour biology. Indeed, the role of eosinophils in malignant conditions, particularly sarcoma, will be an important area for future research.

12. Adamko DJ, Odemuyiwa SO, Vethanayagam D, Moqbel R. The rise of the phoenix: The expanding role of the eosinophil in health and disease. Allergy 2005;60:13-22.

13. Dorta RG, Landman G, Kowalski LP, Lauris JR, Latorre MR, Oliveira DT. Tumour-associated tissue eosinophilia as a prognostic factor in oral squamous cell carcinomas. Histopathology 2002;41:152-7.

14. Takanami I, Takeuchi K, Gika M. Immunohistochemical detection of eosinophilic infiltration in pulmonary adenocarcinoma. Anticancer Res 2002;22:2391-6.

15. Agarwal S, Wadhwa N, Gupta G. Eosinophils as a marker for invasion in cervical squamous neoplastic lesions. Int J Gynecol Pathol 2003;22:213.

16. Itoh $\mathrm{H}$, Hinoura $\mathrm{Y}$, Aratake $\mathrm{Y}$, et al. Cytology of primary cutaneous Langerhans cell histiocytosis with a malignant phenotype. A case report. Acta Cytol 2002;46:731-4.

17. Matsumoto S, Tamai T, Yanagisawa K, Kawamura S, Fujita S. Lung cancer with eosinophilia in the peripheral blood and the pleural fluid. Intern Med 1992;31:525-9.

18. Wardlaw AJ, Kay AB. Eosinophils and their disorders. In: Williams WJ, ed. Hematology, 6th edn. New York: McGraw Hill, 2001:785-99.

19. O'Sullivan MJ, Swanson PE, Knoll J, Taboada EM, Dehner LP. Undifferentiated embryonal sarcoma with unusual features arising within mesenchymal hamartoma of the liver: Report of a case and review of the literature. Pediatr Dev Pathol 2001;4:482-9.

20. Lo Re V III, Fox KR, Ferrari VA, Scott CH, Kossev PM, Kostman JR. Hypereosinophilia associated with cardiac rhabdomyosarcoma. Am J Hematol 2003;74:64-7.

21. Pal L, Parkash V, Chambers JT. Eosinophilia and uterine leiomyosarcoma. Obstet Gynecol 2003;101:1130-2.

22. van Ruth S, van Coevorden F, Peterse JL, Kroon BB. Alveolar soft part sarcoma. A report of 15 cases. Eur J Cancer 2002;38:1324-8. 


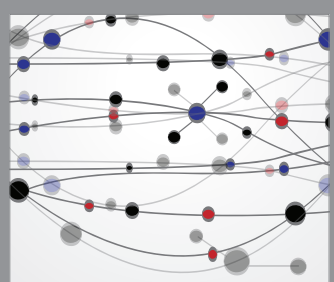

The Scientific World Journal
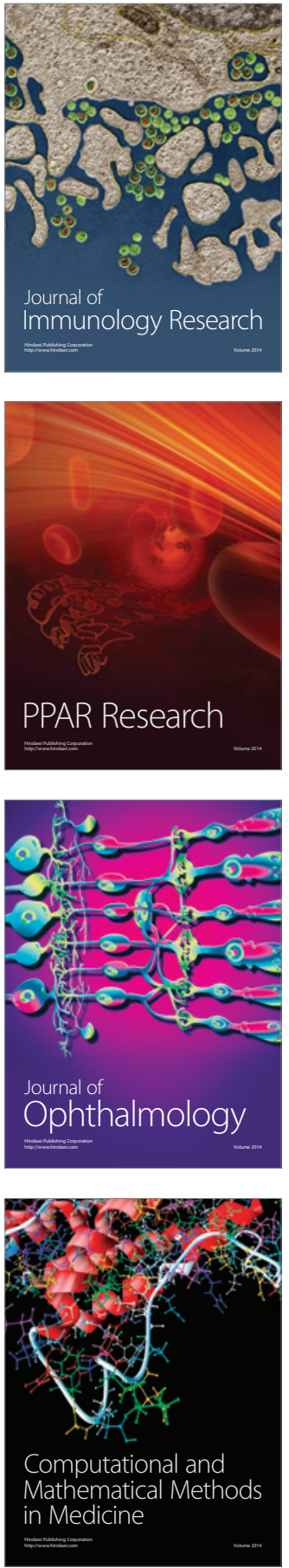

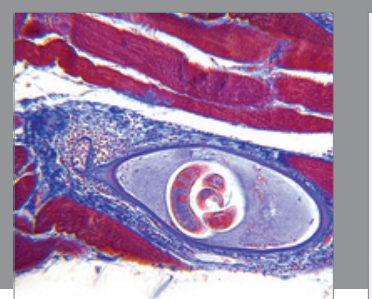

Gastroenterology Research and Practice

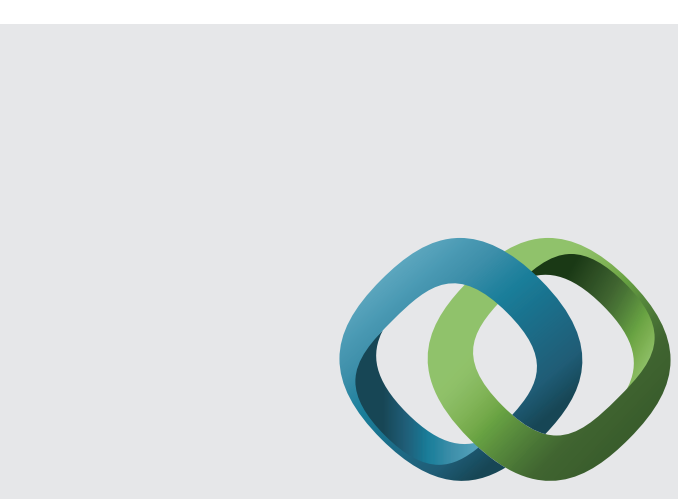

\section{Hindawi}

Submit your manuscripts at

http://www.hindawi.com
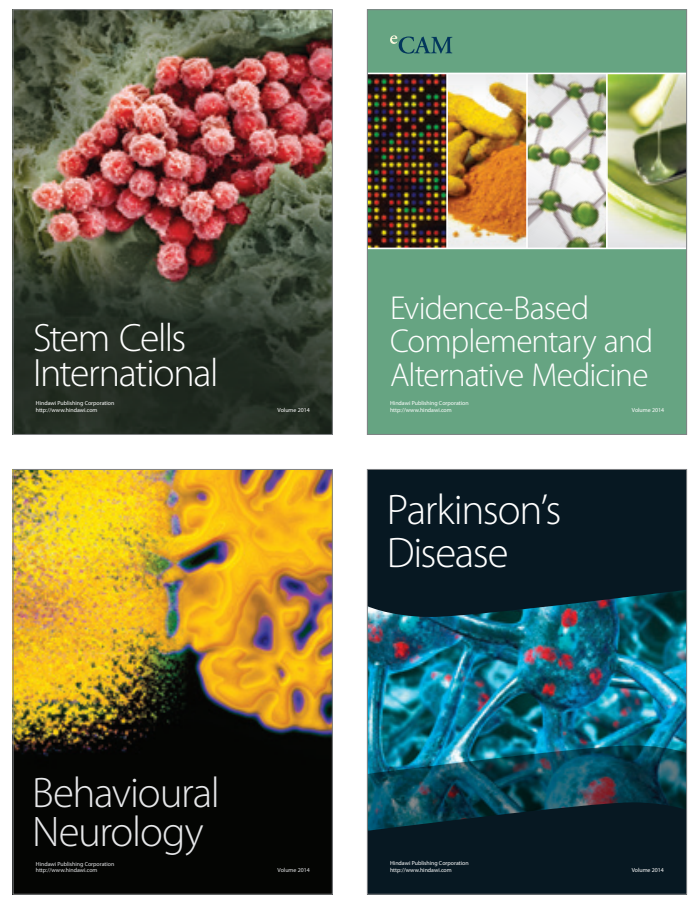
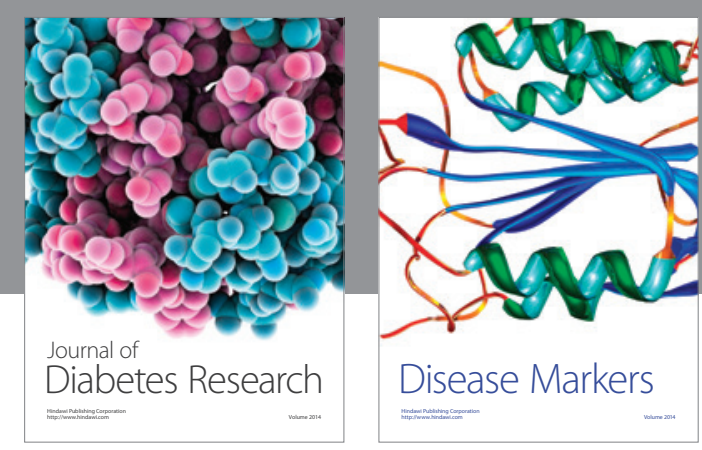

Disease Markers
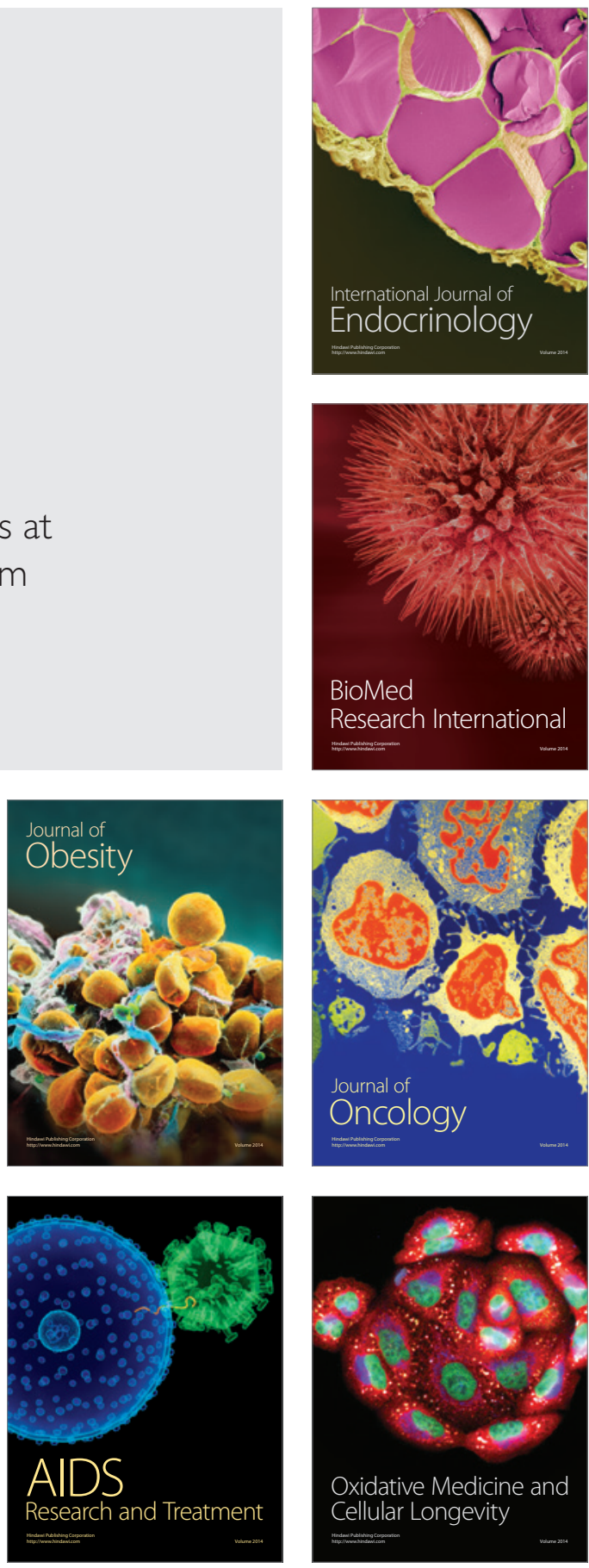